\title{
Henri de Saint-Georges, Hippolyte Monpou, Le Planteur, opéra-comique en deux actes
}

\section{Valentina Ponzetto}

\section{(2) OpenEdition}

1 Journals

\section{Édition électronique}

URL : http://journals.openedition.org/studifrancesi/4410

DOI : 10.4000/studifrancesi.4410

ISSN : 2427-5856

Éditeur

Rosenberg \& Sellier

\section{Édition imprimée}

Date de publication : 1 septembre 2016

Pagination : 345

ISSN : 0039-2944

\section{Référence électronique}

Valentina Ponzetto, « Henri de Saint-Georges, Hippolyte Monpou, Le Planteur, opéra-comique en deux actes », Studi Francesi [En ligne], 179 (LX | II) | 2016, mis en ligne le 01 septembre 2016, consulté le 18 septembre 2020. URL : http://journals.openedition.org/studifrancesi/4410 ; DOI : https://doi.org/ 10.4000/studifrancesi.4410

Ce document a été généré automatiquement le 18 septembre 2020.

\section{(c)}

Studi Francesi è distribuita con Licenza Creative Commons Attribuzione - Non commerciale - Non opere derivate 4.0 Internazionale. 


\title{
Henri de Saint-Georges, Hippolyte Monpou, Le Planteur, opéra-comique en deux actes
}

\author{
Valentina Ponzetto
}

\section{RÉFÉRENCE}

HENRI DE SAINT-GEORGES, HIPPOLYTE MONPOU, Le Planteur, opéra-comique en deux actes, précédé d'un extrait du Voyage aux États-Unis ou tableau de la société américaine de Harriet Martineau et de L'Inventaire du planteur d'Émile Souvestre, et suivi de nombreux documents inédits, présentation de Barbara T. Cooper, Paris, L'Harmattan, 2005, XXXIX-195 pp.

1 Ce volume, agile et coquet sous sa couverture brochée couleur de rose, renferme la remarquable édition critique d'un livret aujourd'hui inconnu: Le Planteur d'Henri de Saint-Georges, opéra-comique mis en musique par Hippolyte Monpou et créé à l'OpéraComique le $1^{\text {er }}$ mars 1839 avec Jenny Colon dans le rôle de l'héroïne, une jeune «négresse blanche» américaine au destin pathétique.

2 Le texte, soigneusement annoté, a été établi à partir de l'édition publiée chez Barba en 1839 dans la collection La France dramatique du XIXe siècle. Une «Annexe» (pp. 117-122), séparée pour ne pas alourdir la lecture, donne les variantes du manuscrit soumis à la censure (Archives Nationales $\mathrm{F}^{18}$ 91).

3 L'intrigue de l'œuvre tire son origine d'un fait divers à l'indéniable potentiel dramatique rapporté par la voyageuse anglaise Harriet Martineau dans son livre Society in America (1837, traduit en français l'année suivante sous le titre Voyage aux États-Unis ou tableau de la société américaine) et déjà repris sous forme de nouvelle par Émile Souvestre en 1838. «Il s'agit d'une jeune femme dont le père, planteur en Louisiane, est mort en laissant des dettes importantes. Un jour, alors que rien - ni la couleur de sa peau, ni la vie qu'elle a menée jusque là - ne laisse soupçonner la vérité, cette jeune 
personne apprend qu'elle est la fille d'une esclave non affranchie et donc, d'après la loi, esclave elle-même. Elle est alors mise aux enchères, avec les autres biens de son père, et se voit adjugée à un planteur qui lui répugne depuis longtemps et dont elle craint le pire» (p. vII). Si dans l'opéra-comique, selon la loi du genre, la fin de l'intrigue est heureuse et voit le triomphe de l'amour et de la vertu, l'histoire soulève néanmoins le problème de l'esclavage des Noirs et des horreurs ratifiées par le Code Noir de la Louisiane.

Barbara Cooper, fine connaisseuse du théâtre français du premier xIx siècle, offre de ce texte une présentation exemplaire, l'entourant d'un très riche apparat anthologique et critique qui le replace dans son contexte et dans les débats du temps, tout en mettant en valeur son intérêt et son actualité pour la critique d'aujourd'hui.

Le livret de Saint-Georges est précédé de ses textes sources: un long extrait du Tableau de la société américaine de Martineau et l'intégralité de la nouvelle L'Inventaire du planteur de Souvestre telle qu'elle parut en trois livraisons dans «Le National» en 1838. Le rapprochement des trois textes de genres et d'auteurs différents, mais dont la filiation est directe, permet à Barbara Cooper de brosser un tableau nuancé et convaincant «de la place occupée par le discours antiesclavagiste dans le paysage français des années 1830 et 1840 » (p. XXIx). Les trois textes participent en effet, à différents degrés, du mouvement abolitionniste, en présentant «les conséquences morales, sociales et économiques de l'esclavage dans le cercle intime d'une famille» (p. xxvIII). Certes, le but didactique et les thèses sociales sont développés de manière plus explicite et directe dans la «nouvelle philanthropique et morale» de Souvestre, avec son dénouement tragique visant à susciter la pitié et l'horreur, et plus encore dans le témoignage non romancé de Martineau. Cependant des traces en persistent encore dans l'atmosphère plus légère et souriante de l'opéra-comique, notamment avec le personnage du mulâtre fashionable, qui se voudrait blanc et dandy, et avec celui de la «négresse blanche», «d'autant plus troublante qu'elle est belle et ressemble à n'importe quelle femme élégante de la métropole» (p. xx).

On pourra sans doute regretter l'absence de la partition de Monpou et d'un commentaire musical, effet collatéral de la rigueur scientifique de l'auteur, qui estime ne pas avoir «les compétences requises» (p. xI) pour cet aspect de l'œuvre. On saluera en revanche un dossier très complet sur la mise en scène (pp. 135-136) et la réception du Planteur, comprenant la transcription intégrale d'une trentaine de comptes rendus pour la création et la reprise de 1867 (pp.137-194), qui nous permettent d'apprécier pleinement les réactions des contemporains face à l'œuvre et à ses thématiques antiesclavagistes.

7 À une époque où les études postcoloniales se taillent une place de plus en plus importante dans le panorama critique, ce volume de Barbara Cooper montre la voie en réunissant la rigueur, l'intelligence et la grâce. 